\title{
Fenologia de Galianthe palustris (Cham. \& Schltdl.) Cabaña Fader \& E. L. Cabral (Rubiaceae Juss.) na região do planalto Catarinense
}

\author{
Phenology of Galianthe palustris (Cham. \& Schltdl.) Cabaña Fader \& E. L. Cabral \\ (Rubiaceae Juss.) in Santa Catarina plateau region
}

\begin{abstract}
Joyce Graziela Maia Furtado Tigre de Oliveira ${ }^{1 *}$ (ORCID 0000-0001-6850-0683), Bruno Jan Schramm Corrêa ${ }^{1}$ (ORCID 0000-0003-3528-4042), Larissa Bittencourt ${ }^{1}$ (ORCID 0000-0002-8362-9351), Adelar Mantovani ${ }^{1}$ (ORCID 0000-0003-2952-2171), Jaçanan Eloisa de Freitas Milani (ORCID 0000-0002-4831-2551), Roseli Lopes da Costa Bortoluzzi' (ORCID 0000-00027445-7244)
\end{abstract}

1Universidade do Estado de Santa Catarina, Lages, SC, Brasil. *Autor para correspondência: joyce.tigre@hotmail.com ${ }^{2}$ Universidade Federal de Mato Grosso, Cuiabá, MT, Brasil.

Submissão: 24/06/2021 / Aceite: 14/10/2021

\begin{abstract}
RESUMO
O objetivo deste estudo foi realizar o monitoramento fenológico de G. palustris ao longo dos meses de julho/2019 a junho/2020, e correlacionar com as variáveis meteorológicas na Serra Catarinense. Foram avaliadas a intensidade e sincronia das fenofases vegetativas e reprodutivas de 24 indivíduos em três áreas, localizadas em dois municípios de Santa Catarina, Brasil. Em G. palustris foi identificada a brotação contínua. Foi observada a presença de folhas maduras durante todo período e a senescência foliar apresentou intensidades variadas. A floração iniciou em dezembro estendendo até abril. As maiores porcentagens de botões florais presentes nas plantas ocorreram de janeiro a março/20 e a antese ocorreu de janeiro a maio, com maiores porcentagens em janeiro e março. Quanto à frutificação, foi observado o início com a presença de frutos imaturos em janeiro se estendendo até junho, mas o período de janeiro a março foi identificado com as maiores porcentagens de frutos imaturos nas plantas. A ocorrência de frutos maduros foi verificada nos meses de fevereiro a junho, sendo em fevereiro e março registradas as maiores porcentagens. Foi identificada a ausência de frutos senescentes somente nos meses de dezembro/2019 e janeiro/2020, e as maiores porcentagens ocorreram nos períodos de outono e inverno, coincidindo com a presença de folhas senescentes. Houve correlação entre temperatura e fotoperíodo para folhas maduras, desfolhamento e botões florais. A sincronia dos eventos fenológicos foi alta para aspectos vegetativos e baixa ou assíncrona para aspectos reprodutivos. Os padrões fenológicos da fenofase reprodutiva foram sazonais, ocorrendo no verão e outono (novembro a junho). Já a fenofase vegetativa ocorreu o ano todo, sendo que os maiores índices de brotação antecederam o período reprodutivo. Os resultados obtidos forneceram informações importantes acerca da fenologia desta espécie nesta região de ocorrência.
\end{abstract}

PALAVRAS-CHAVE: fenofases, planta medicinal, biodiversidade, erva-de-lagarto.

\section{ABSTRACT}

The objective of this study was to carry out the phenological monitoring of G. palustris over the months of July/2019 to June/2020, and to correlate with the meteorological variables in the Serra Catarinense. The intensity and synchrony of the vegetative and reproductive phenophases of 24 individuals in three areas, located in two municipalities of Santa Catarina, Brazil, were evaluated. In G. palustris, continuous sprouting was identified. The presence of mature leaves was observed throughout the period and the leaf senescence showed varying intensities. Flowering started in December extending until April. The highest percentages of flower buds present on the plants occurred from January to March and anthesis occurred from January to May, with the highest percentages in January and March. As for fruiting, the beginning was observed with the presence of immature fruits in January extending until June, but the period from January to March was identified with the highest percentages of immature fruits in the plants. The occurrence of ripe fruits was verified from February to June, with the highest percentages being recorded in February and March. The absence of senescent fruits was identified only in the months of December/2019 and January/2020, and the highest percentages occurred in the autumn and winter periods, coinciding with the presence of senescent leaves. There was a correlation between temperature and photoperiod for mature leaves, defoliation and flower buds. The synchrony of the phenological events was high for vegetative aspects and low to asynchrony for reproductive aspects. The phenological patterns of reproductive phenophase were seasonal, 
occurring in the summer and autumn (November to June). The vegetative phenophase occurred throughout the year, with the highest budding rates preceding the reproductive period. The results obtained provided important information about the phenology of this species in this region of occurrence.

KEYWORDS: phenophases, medicinal plant, biodiversity, erva-de-lagarto.

\section{INTRODUÇÃO}

O Brasil ocupa o primeiro lugar em biodiversidade e possui a segunda maior área florestada do planeta (GANEM 2010, MMA 2020). O domínio de vegetação brasileira com maior riqueza é o bioma Mata Atlântica (MMA 2020, SEMA 2009), considerado o mais rico dos domínios fitogeográficos, abrigando mais de 17.800 espécies vegetais, destas, e aproximadamente 10.500 espécies são endêmicas (FLORA DO BRASIL 2020, MYERS et al. 2000). Mas, devido as grandes alterações e o cenário de elevada fragmentação (ELIAS et al. 2016, GANEM 2010), está incluído como um dos 34 hotspots de biodiversidade (MITTERMEIER et al. 2004), com prioridade para conservação, portanto é protegido por Lei (BRASIL 2006).

O bioma Mata Atlântica possui uma flora rica em espécies nativas com princípios ativos medicinais (MING et al. 2012), as quais são amplamente utilizadas na medicina popular. Devido à essa característica, muitos estudos são realizados no bioma, em diversos âmbitos, e dentre esses, uma área de estudo que vem evoluindo significativamente é referente às potencialidades terapêuticas (OLIVEIRA et al. 2009, CARTAXO et al. 2010), ou seja, a identificação de espécies com potencial medicinal.

A família Rubiaceae Juss. está inserida no clado das Eudicotilêdoneas, na ordem Gentianales. No Brasil são reconhecidos, na família Rubiaceae, 129 gêneros, 1408 espécies, 41 subespécies, 58 variedades; destes 14 gêneros, 714 espécies, 23 subespécies e 28 variedades são endêmicos no país, com distribuição em todos os Estados e domínios fitogeográficos e praticamente em todos os tipos de fitofisionomias do país (FLORA DO BRASIL 2020).

Estudos sobre os ciclos reprodutivos de espécies de Rubiaceae indicam que, geralmente, as populações apresentam floração sazonal, com pico de produção de flores na estação chuvosa ou seca, e frutificação mais frequente na estação chuvosa (ALMEIDA \& ALVES 2000, COELHO \& BARBOSA 2004, FERREIRA \& CONSOLARO 2013). E, devido à sua abundância e diversidade é uma família importante a ser pesquisada, principalmente em estudos de composição florística e fitossociológica, comparações entre estratos vegetais, habitats e status de conservação de vegetações tropicais (DELPRETE \& JARDIM 2012), além das características medicinais das espécies pertencentes a ela.

Um dos gêneros de Rubiaceae que mais se destaca pelo uso medicinal é Coffea, popular café (DI STASI \& HIRUMA-LIMA 2002). Dentre outros gêneros está Borreria (atualmente considerado, em parte, no gênero Galianthe) com ampla utilização medicinal já comprovada para suas raízes, parte aérea e flores (CONSERVA \& FERREIRA 2012).

Galianthe palustris (Cham. \& Schltdl.) Cabaña Fader \& E. L. Cabral é uma espécie herbácea prostrada, estolonífera e muito ramificada com ocorrência confirmada na Bahia, Distrito Federal, Goiás, Espírito Santo, Minas Gerais, Rio de Janeiro, São Paulo, Paraná, Rio Grande do Sul e Santa Catarina (FLORA DO BRASIL 2020). Para G. palustris já foi relatado atividade enzimática e potencial alelopático de seu caule, folhas e flores (DENARDIN et al. 2018), porém, a espécie necessita ser melhor estudada quanto a sua biologia e dinâmica reprodutiva.

A oferta de material biológico para pesquisas e consumo medicinal está relacionada ao período e disponibilidade para coleta ao longo do ano. Desta forma, estudos sobre fenologia definem quais os fatores ambientais que influem em suas fenofases e permitem inferir qual a melhor época para coleta de flores, frutos e folhas. Assim, o objetivo deste estudo foi realizar o acompanhamento fenológico de populações naturais de Galianthe palustris na Serra Catarinense.

\section{MATERIAL E MÉTODOS}

O estudo foi realizado no Planalto Sul Catarinense com clima predominantemente Cfb (subtropical úmido e temperatura média do mês mais quente inferior a $22^{\circ} \mathrm{C}$ ), segundo a classificação de Köppen (ALVARES et al. 2017).

As três áreas de estudo são particulares, se caracterizam como pequenas propriedades rurais, com uso e ocupação do solo predominantemente por pecuária. A área 1 e 3 são aproximadamente $2 \mathrm{~km}$ de distância entre si e localizam-se em São José do Cerrito (2739'42"S 50³4'42"O), município que conta com uma altitude de 921 metros. A Área 2 está aproximadamente a $19 \mathrm{~km}$ de distância entre as demais áreas e

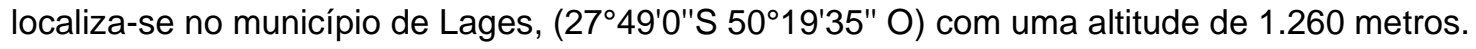




\section{Preparo do material botânico para catalogação e armazenamento}

Espécimes de Galianthe palustris, representativos de cada área amostral (sendo Área 1 - Localidade Cedro Alto; Área 2 - Localidade Passo dos Fernandes e Área 3 - Localidade Pinheiros Ralos) foram coletados, processados e desidratados em estufa (cerca de $50 \stackrel{\circ}{\circ}$ ), catalogados e depositados na coleção do Herbário Lages, da Universidade do Estado de Santa Catarina - LUSC. As duplicatas foram encaminhadas para outras coleções do Estado. Além das coletas, também foram feitos registros fotográficos das espécies e do seu local de ocorrência (preferência de hábitat).

\section{Acompanhamento fenológico de Galianthe palustris}

Foram instaladas quatro parcelas de $2 \times 2 \mathrm{~m}$ em cada área de estudo, nas quais foi realizado, quinzenalmente, o monitoramento fenológico de dois indivíduos de G. palustris por parcela, totalizando 24 indivíduos, durante 12 meses, no período de julho de 2019 a junho de 2020. De acordo com o método descrito por MORELLATO et al. (1989) foram avaliadas a seguintes fenofases: vegetativa (Folhas senescente, folhas maduras, brotações), reprodutiva (botão floral, antese, frutos imaturos, frutos maduros e frutos senescentes) (Figura 1).
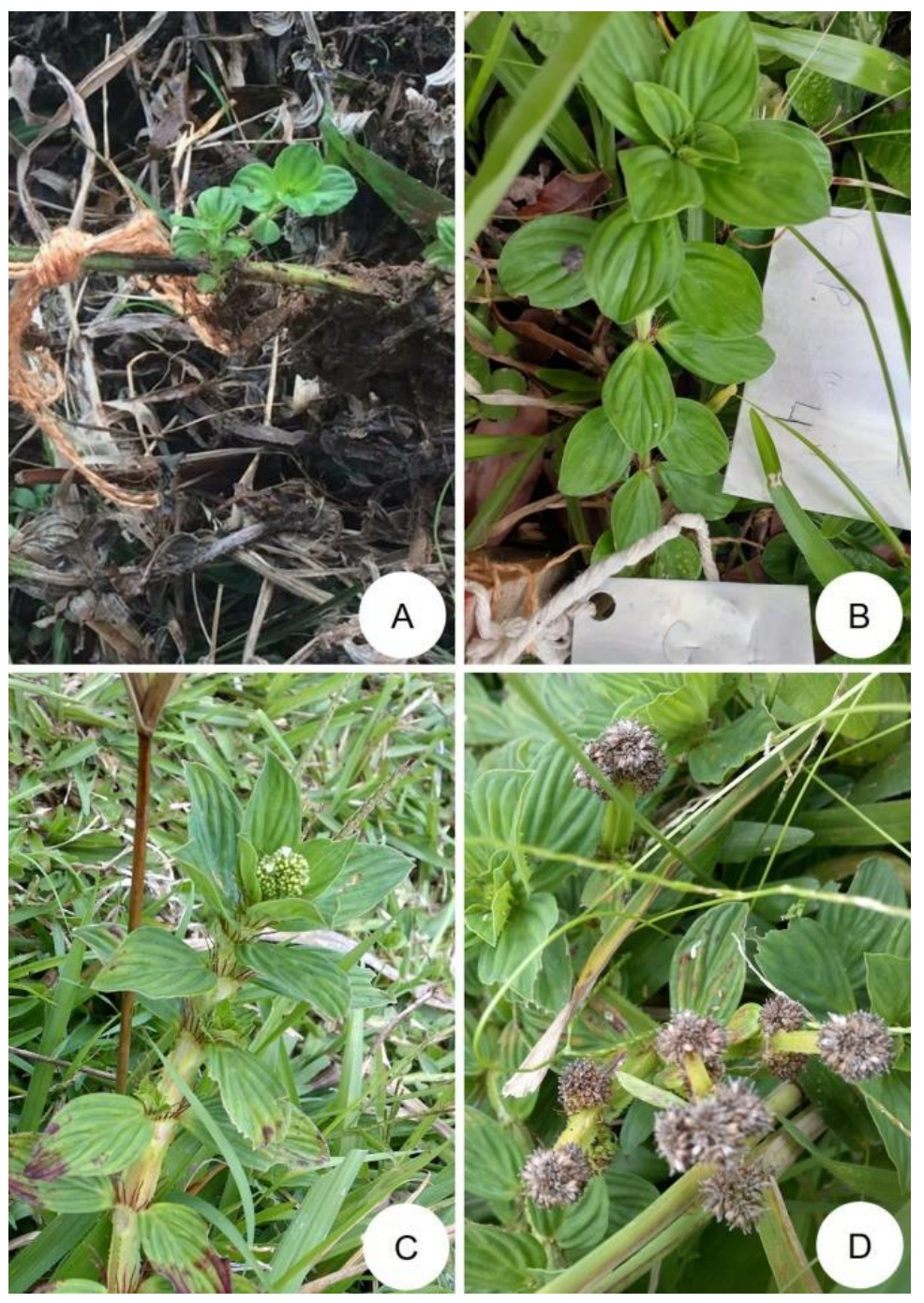

Figura 1. Fenofases de Galianthe palustris. (A) Brotamento; (B) Ramos com folhas maduras; (C) Ramos com botões florais; (D) Ramos com frutos maduros.

Figure 1. Phenophases of Galianthe palustris. (A) Budding; (B) Branches with mature leaves; (C) Branches with flower buds; (D) Branches with ripe fruits.

Para caracterizar as fenofases da espécie foi utilizado o índice de atividade), método onde é constatada a presença (1) ou ausência (0) da fenofase no indivíduo, não estimando intensidade ou quantidade da fenofase (FOURNIER 1974). Esse método de análise tem caráter qualitativo em nível individual, mas quantitativo em nível populacional, indicando a porcentagem de indivíduos da população que está em determinado evento fenológico. O método também estima a sincronia entre os indivíduos de uma população, levando-se em conta que, quanto maior o número de indivíduos manifestando a fenofase ao mesmo tempo, 
maior é a sincronia desta população (BENCKE \& MORELLATO 2002). Sendo assim, o evento fenológico será considerado assincrônico quando presente até $20 \%$ de indivíduos avaliados na fenofase; pouco sincrônico ou com baixa sincronia de $20-60 \%$ de indivíduos na fenofase; sincronia alta, maior de $60 \%$ dos indivíduos na fenofase (MARCHIORETTO et al. 2007, SOUZA et al. 2014).

\section{Análise de dados}

Para verificar a influência dos fatores climáticos no comportamento fenológico foi realizada a análise de correlação de Spearman $(\mathrm{rs})$ a partir de dados médios para as variáveis: precipitação $(\mathrm{mm})$, temperatura mínima $\left({ }^{\circ} \mathrm{C}\right)$, temperatura máxima $\left({ }^{\circ} \mathrm{C}\right)$ e insolação $(\mathrm{h}), 30$ dias antes do início do estudo de cada espécie e, posteriormente, ao início do estudo, foi feito a média a cada 15 dias. Todas as análises foram feitas com o auxílio do software $R \circledast$ versão 3.2.2, utilizando a biblioteca Vegan (OKSANEN et al. 2010). Os dados meteorológicos diários de temperatura mínima, média e máxima $\left({ }^{\circ} \mathrm{C}\right)$, precipitação $(\mathrm{mm})$ e fotoperíodo foram fornecidos pela EPAGRI/CIRAM (Centro de Informações de Recursos Ambientais e de Hidrometeorologia de Santa Catarina).

\section{RESULTADOS E DISCUSSÃO}

Devido às semelhanças nos padrões fenológicos entre as áreas de estudo, e por não haver diferença significativa entre as áreas, a caracterização do comportamento fenológico e as análises de correlação foram realizadas considerando todos os indivíduos monitorados nas três áreas.

De acordo com os dados climáticos para região do período avaliado, observou-se pico na insolação em dezembro, com 13,7 horas de sol. A média do período de estudo foi de 12,1 horas de sol por dia. O menor tempo de disponibilidade solar ocorreu em junho, com 10,3 horas.

As temperaturas mais baixas ocorreram em julho/2019 e junho/2020, durante o inverno, enquanto as maiores temperaturas incidiram sobre os meses de novembro/2019 até março/2020, durante o verão. Os meses com maiores quantidades de chuva acumulada foram outubro e novembro de 2019 (Figura 2).

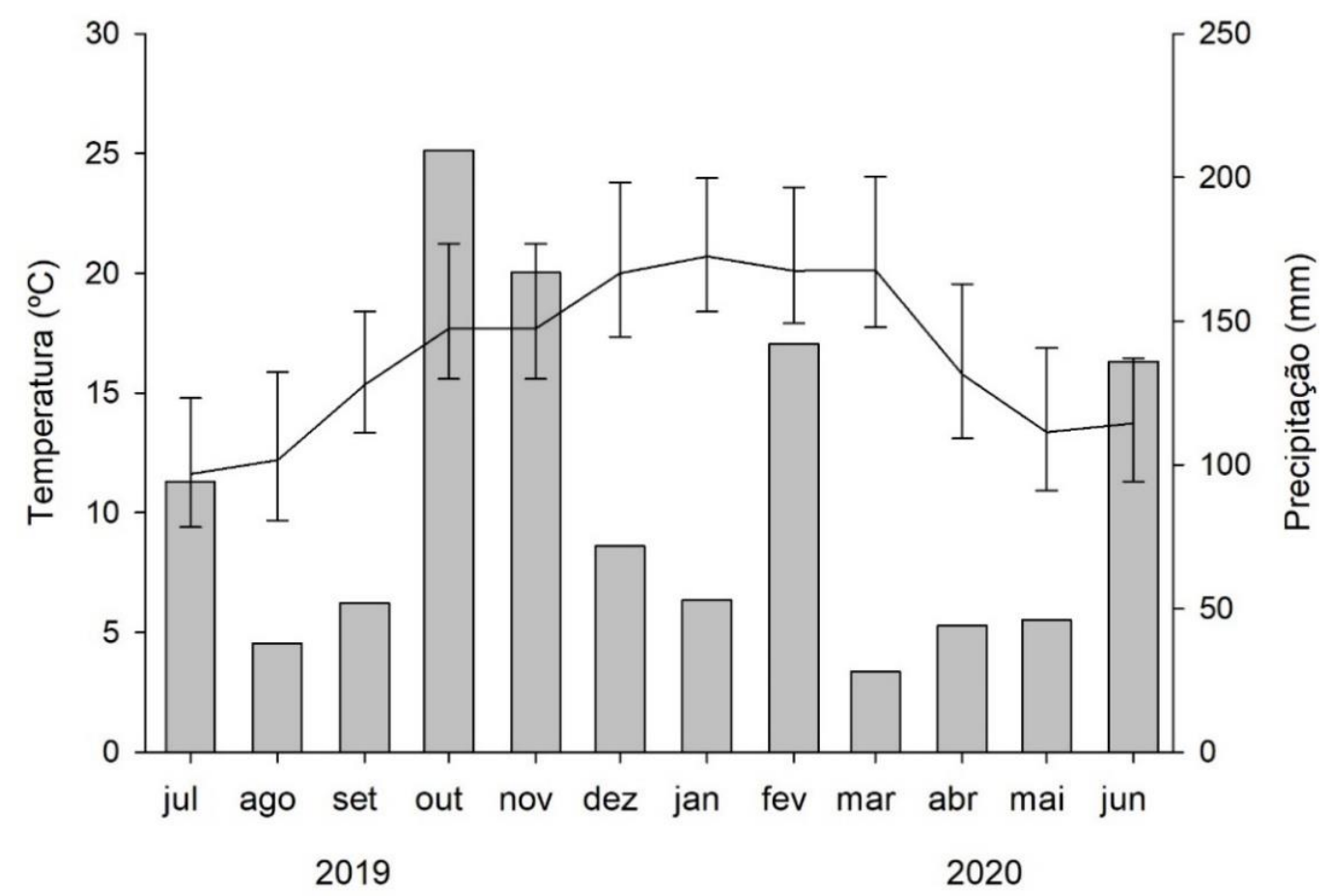

Fonte: Elaborado pela autora (2020) com dados da EPAGRI/CIRAM.

Figura 2. Temperaturas mínima, média e máxima e precipitação na Serra Catarinense entre julho de 2019 a junho de 2020.

Figure 2. Minimum, average and maximum temperatures and precipitation in Santa Catarina's plateau between July 2019 and June 2020.

Quanto à intensidade das fenofases vegetativas de G. palustris (Figura 3), foi verificada que a brotação ocorreu durante todo período de avaliação, com maior incidência de julho/2019 a fevereiro/2020, com percentuais de $100 \%$ de agosto a janeiro e diminuição da intensidade a partir de fevereiro de 2020 . 


\section{Fenofases Vegetativas}

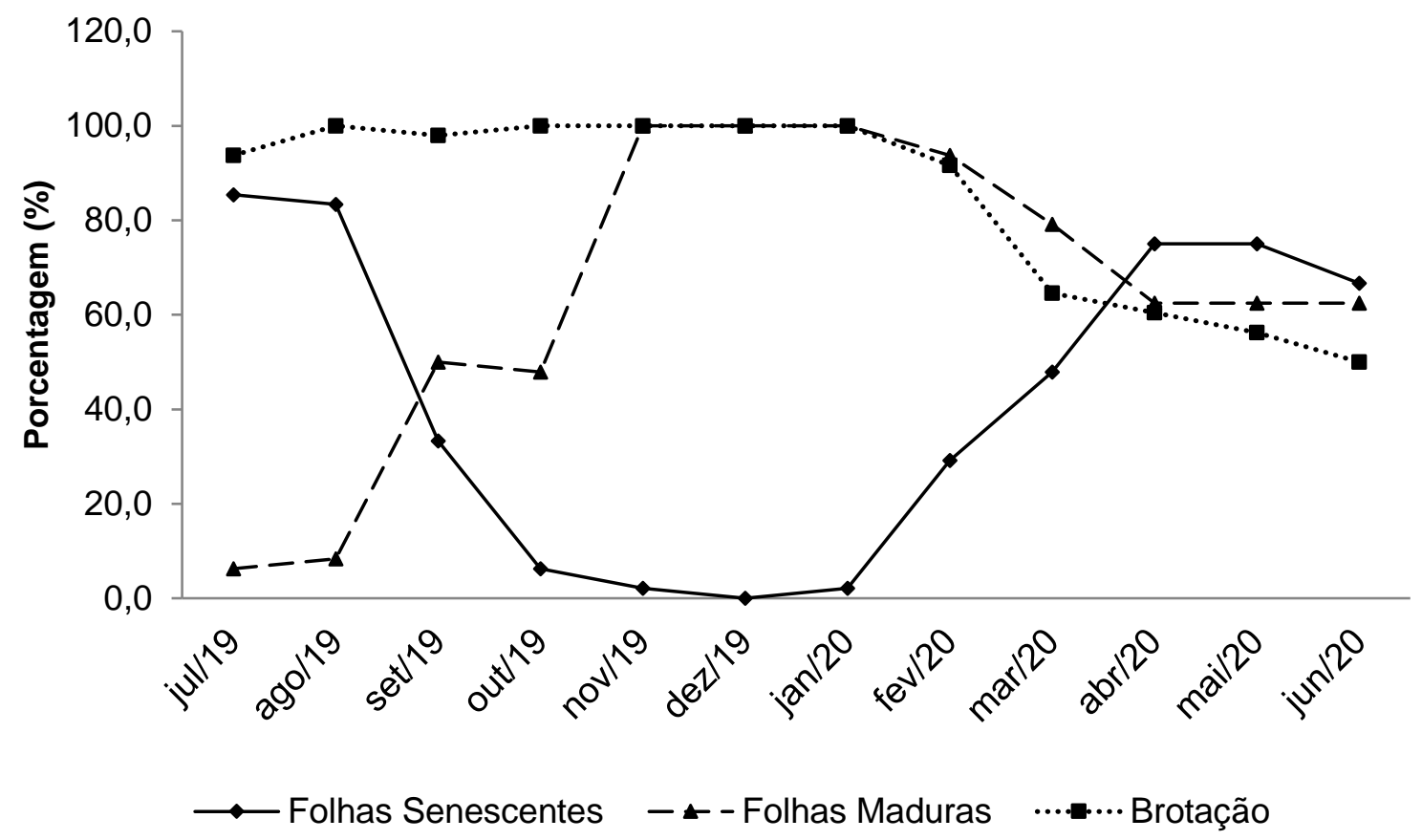

Figura 3. Gráfico de intensidade das fenofases vegetativas de Galianthe palustris, com as porcentagens médias dos meses de monitoramento, iniciado em julho/2019 até junho/2020.

Figure 3. Vegetative phenophase intensity graph of Galianthe palustris, with the average percentages of the monitoring months, starting in July/2019 until June/2020.

A presença de folhas maduras foi constante nas plantas durante todo período de avaliação (Figura 3), com maior intensidade durante o período de novembro/2019 a fevereiro/2020, com média de $98,4 \%$. Nos meses de julho e agosto/2019 a porcentagem média de folhas maduras nas plantas foi de 7,3\%.

Os indivíduos apresentaram perda foliar gradual e progressiva, onde a senescência foliar foi observada em 11 meses de avaliação com porcentagens variadas (Figura 3), exceto no mês de dezembro/2019. Os meses de julho e agosto/2019 foram os que apresentaram maior número de folhas senescentes com média de $84,4 \%$. Já o período de outubro/2019 a janeiro/2020 foi o com menor porcentagem de presença de folhas senescentes (média de 2,6\%).

A fenofase vegetativa foi observada durante todo o período de monitoramento da espécie e, ainda, foi observado que durante o período de maior incidência de brotações houve um decréscimo nas folhas senescentes, e um acréscimo de folhas novas e maduras.

Os primeiros indícios de floração, com a formação de botões florais iniciaram em dezembro/2019 se estendendo até Abril/2020, em torno de de 19,6\% (Figura 4). As maiores porcentagens de botões florais presentes nas plantas ocorreram de Janeiro a Março/2020, com média de 25,7\%. A antese ocorreu de Janeiro a Maio/2020, com média de 16,3\%, e, as maiores porcentagens ocorreram entre Março e Abril (Figura 4).

Quanto à frutificação foi observado o início com a presença de frutos imaturos em Janeiro/2020 com ocorrência até Junho/2020, os períodos de janeiro/20 a março/20 foram identificados com as maiores porcentagens de presença de frutos imaturos nas plantas (Figura 5).

A ocorrência de frutos maduros foi verificada do mês de Fevereiro/2020 a Junho/2020, sendo fevereiro e março as maiores porcentagens. Foi identificada a ausência de frutos senescentes somente nos meses de dezembro/2019 e janeiro/2020, e as maiores porcentagens foram, preferencialmente, nos períodos de outono (maio) e inverno (setembro), coincidindo com a presença de folhas senescentes. O período de frutificação inicia aproximadamente um mês após o início do aparecimento de botões florais.

Quanto à sincronia dos eventos fenológicos, de acordo com as análises de dados, todas as etapas da fenofase vegetativa apresentaram alta sincronia com média de $63 \%$ dos indivíduos na mesma fenofase. Já para a fenofase reprodutiva, todas as etapas apresentaram baixa sincronia a assincronia, variando de 16 a $20 \%$.

No que diz respeito a brotação, esta não obteve correlação com nenhuma das variáveis (Tabela 1). 


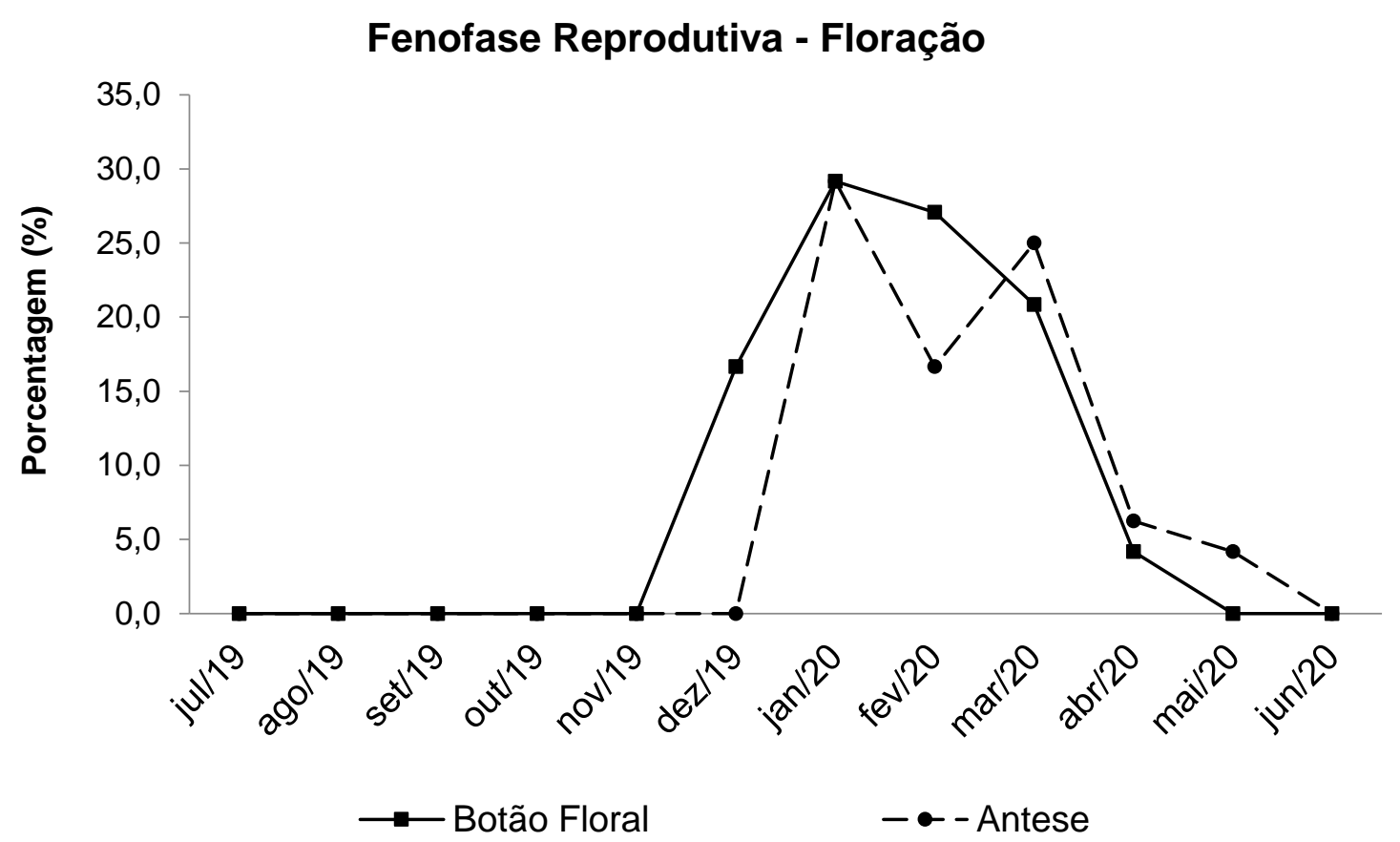

Figura 4. Gráfico do período de floração de Galianthe palustris, com as porcentagens médias dos meses de monitoramento, iniciado em julho/2019 até junho/2020.

Figure 4. Graph of the flowering period of Galianthe palustris, with the average percentages of the months of monitoring, starting in July/2019 until June/2020.

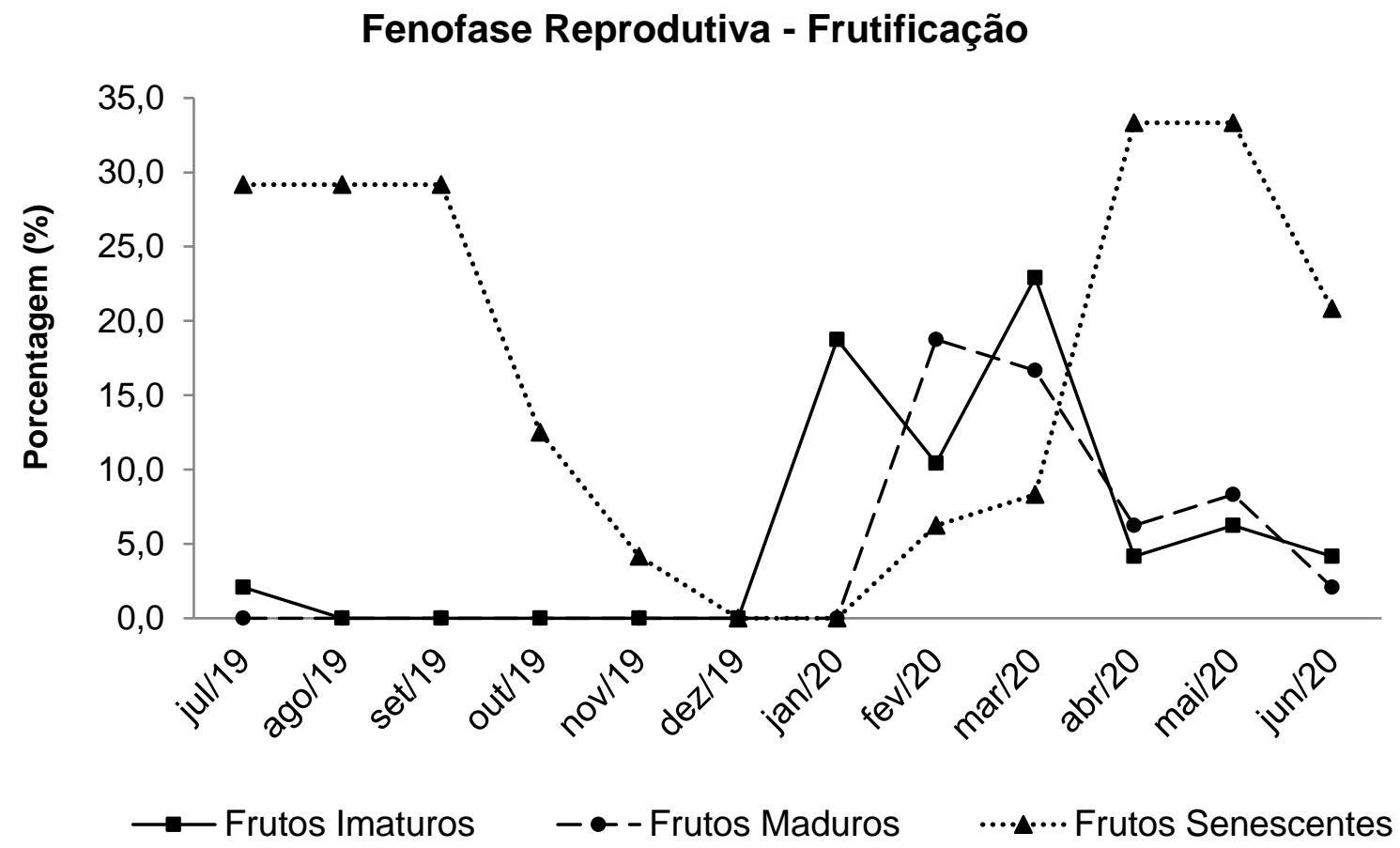

Figura 5. Gráfico do período de frutificação de Galianthe palustris, com as porcentagens médias dos meses de monitoramento, iniciado em julho/2019 até junho/2020.

Figure 5. Graph of the fruiting period of Galianthe palustris, with the average percentages of the monitoring months, starting in July/2019 until June/2020. 
Tabela 1. Correlação de Spearman* entre as fenofases e as variáveis climáticas (precipitação mensal, médias mensais de temperatura máxima, média, mínima e fotoperíodo) em população de Galianthe palustris na serra de Santa Catarina, Brasil.

Table 1. Spearman correlation between phenophases and climatic variables (monthly rainfall, monthly averages of maximum, average, minimum and photoperiod temperature) in a population of Galianthe palustris in the plateau region in Santa Catarina, Brazil.

\begin{tabular}{|c|c|c|c|c|c|}
\hline Fenofases & $\begin{array}{c}\text { Precipitação } \\
\text { Mensal }\end{array}$ & $\begin{array}{c}\text { Temp. Máx. } \\
\left({ }^{\circ} \mathrm{C}\right)\end{array}$ & $\begin{array}{c}\text { Temp. Méd. } \\
\left({ }^{\circ} \mathrm{C}\right)\end{array}$ & $\begin{array}{c}\text { Temp. Mín. } \\
\left({ }^{\circ} \mathrm{C}\right)\end{array}$ & Fotoperíodo \\
\hline \multirow{2}{*}{ Brotação } & 0,25 & 0,29 & 0,27 & 0,28 & 0,46 \\
\hline & $p(0,4059)$ & $p(0,3284)$ & $p(0,3784)$ & $p(0,3466)$ & $p(0,1238)$ \\
\hline \multirow{2}{*}{ Folha Madura } & 0,33 & 0,69 & 0,71 & 0,75 & 0,79 \\
\hline & $p(0,2784)$ & $p(0,0223)^{* *}$ & $p(0,019)^{* *}$ & $p(0,0124)^{* *}$ & $p(0,0086)^{* *}$ \\
\hline \multirow{2}{*}{$\begin{array}{l}\text { Folha } \\
\text { Senescente }\end{array}$} & $-0,36$ & $-0,76$ & $-0,75$ & $-0,77$ & $-0,82$ \\
\hline & $p(0,2367)$ & $p(0,0118)^{\star *}$ & $p(0,0131)^{\star \star}$ & $p(0,0104)^{\star *}$ & $p(0,0067)^{\star *}$ \\
\hline \multirow{2}{*}{ Botão Floral } & $-0,20$ & 0,78 & 0,81 & 0,78 & 0,80 \\
\hline & $p(0,5172)$ & $p(0,0094)^{\star *}$ & $p(0,0072)^{\star \star}$ & $p(0,0094)^{* *}$ & $p(0,0083)^{\star \star}$ \\
\hline \multirow{2}{*}{ Fruto Imaturo } & $-0,27$ & 0,19 & 0,34 & 0,29 & 0,16 \\
\hline & $p(0,3742)$ & $p(0,5367)$ & $p(0,2574)$ & $p(0,3295)$ & $p(0,6037)$ \\
\hline \multirow{2}{*}{ Fruto Maduro } & $-0,26$ & 0,20 & 0,21 & 0,17 & 0,02 \\
\hline & $p(0,3926)$ & $p(0,5164)$ & $p(0,4916)$ & $p(0,5680)$ & $p(0,9381)$ \\
\hline
\end{tabular}

*Valores p abaixo de 0,05 indicam correlações estatisticamente significativas não-zero no nível de confiança de 95,0\%. ** Correlações estatisticamente significativas no nível de confiança de 95,0\%.

As folhas maduras, desfolhamento e botões florais tiveram correlação significativamente com temperatura mínima, média, máxima e fotoperíodo, já a frutificação (fruto imaturo e maduro) não apresentou correlação com nenhuma das variáveis ambientais. Ressalta-se que a precipitação mensal não interagiu com nenhuma das fenofases avaliadas.

A brotação contínua de Galianthe palustrisao longo do ano, já foi evidenciada em Borreria poayana na região do Cerrado (MUNHOZ \& FELFILI 2005). Já em B. suaveolens, o período de brotação apresenta-se mais tardio, sendo de outubro a fevereiro (MARTINI et al. 2010). Em outras espécies da família Rubiaceae também foi identificado brotações contínuas, sendo que para Amaioua intermedia a maior intensidade, ocorreu de Julho a Abril (TALORA \& MORELLATO 2000); para Psychotria poeppigiana Mull. Arg. foi mais intensa de março a agosto (COELHO \& BARBOSA 2004); e para $P$. carthagenensis Jacq sendo de fevereiro a maio (LOCATELLI \& MACHADO 2004). Devido às condições climáticas distintas das regiões é comun a ocorrência de eventos fenológicos em épocas diferentes.

O brotamento foliar aparentemente não responde a nenhuma variável ambiental levantada e esta característica pode estar relacionada a baixa oscilação desta variável durante o ano de estudo e ao nível raso de sincronismo, semelhante ao observado em Guazuma ulmifolia Lam. (Malvaceae) (NUNES et al. 2005)

Durante todo o período de estudo, essas plantas mantiveram as folhas maduras, característica também observada em Borreria poaya, sendo que as folhas maduras observadas surgiram de dezembro a junho (MUNHOZ \& FELFILI 2005). A transição entre brotação e folhas maduras foi observada em poucos meses, permitindo a renovação constante das folhas senescentes. A correlação das folhas maduras com as variáveis de temperatura e fotoperíodo permitem inferir que o desenvolvimento foliar se deve a estes fatores. As muitas respostas das plantas às mudanças nas condições de luz e temperatura levam à otimização do desenvolvimento da folha para usar a luz para a fotossíntese (SCHULZE et al. 2019),

O aumento da brotação ocorreu na primavera e início do verão antes da fase reprodutiva, que é uma forma de ganhar mais energia para a reprodução futura. Durante o pico de brotação e amadurecimento foliar, a diminuição da queda foliar pode estar relacionada a uma estratégia da planta para utilizar toda a sua energia na renovação foliar em um mesmo momento, assim, quando ocorrer a troca de estação, suas folhas estejam totalmente formadas (TAIZ \& ZEIGER 2013).

O aumento da senescência foliar, de maneira geral, ocorreu no começo do outono se intensificando no inverno, coincidindo com uma média de temperatura de $14^{\circ} \mathrm{C}$ durante este período (com temperaturas abaixo de zero), o que pode ser um mecanismo de defesa contra as temperaturas negativas (LARCHER 2006) e geadas (INOUYE 2000), muito comuns na região. 
A correlação do desfolhamento com a temperatura (máxima, média e mínima) e a incidência solar (variáveis que foram as principais responsáveis pela queda foliar intensa durante o pico do inverno e suspenção do desfolhamento durante o verão) convergem com estudos fenológicos em regiões subtropicais dependentes da mudança de temperatura e incidência solar na senescência foliar, indicando que o principal indutor da senescência foliar é a diminuição da temperatura do ar, decorrente do estreitamento da oferta de luz solar (TAIZ \& ZEIGER 2013, FERRERA et al. 2017, CORRÊA et al. 2018).

Em um estudo taxonômico do gênero Borreria realizado na Bahia por CABRAL et al. (2011) os autores citam que a floração e frutificação da Borreria palustris (atual Galianthe palustris) ocorre quase todo o ano, diferindo dos resultados do presente estudo devido as características ambientais e climáticas distintas. Outras espécies também apresentaram diferenças entre estudos, como $B$. verticillata que foi analisada quanto a floração e frutificação com incidência de outubro a maio, ou ainda, entre novembro a janeiro e abril e junho (VARJÃO et al. 2013). O estudo de MELO \& BARBOSA (2007) relata a floração da $B$. verticillata durante junho, julho e setembro, em área de Caatinga na Paraíba, demonstrando que o período das fenofases diferem para a mesma espécie dependendo da localidade, temperaturas e quantidade de precipitação. Portanto é importante a realização de estudos fenológicos para as espécies vegetais em áreas de estudos distintas (FELIPPI et al. 2012).

Resultados semelhantes ao presente estudo também foram observados em Borreria suaveolens com período de floração (botão floral + antese) de dezembro a abril (MARTINI et al. 2010). Este período de cerca de cinco meses de floração caracterizou uma floração extensiva ou longa floração como discutido por BAWA \& BEACH (1983). O fornecimento de flores ao longo do ano está relacionado ao tipo de floração em estado estacionário, sob o qual o polinizador pode ser mantido, fornecendo assim recursos florais constantes. A disponibilidade de flores ao longo do ano está ligada a categoria de floração do tipo steady state, onde é feita a manutenção dos polinizadores, ofertando recurso floral constante (OTAROLA \& ROCCA 2014).

Segundo CASTELLANI et al. (1999) as fenofases reprodutivas tem estímulos positivos com maior exposição solar e aumento de temperatura, o que corrobora com os dados obtidos no presente estudo, já que as maiores porcentagens de floração e início da frutificação ocorreram no verão. De fato, a floração de $G$. palustris apresentou correlação com a temperatura mínima, média, máxima e fotoperíodo. Em plantas tropicais este comportamento é característico, pois estas variáveis influem no desenvolvimento reprodutivo das plantas com o ambiente, garantindo a fecundação cruzada e, portanto, a recombinação gênica em condições ambientais favoráveis (KERBAUY 2008). FERRERA et al. (2017) e ATHAYDE et al. (2009) obtiveram resultados semelhantes com florações de espécies arbóreas nativas do Rio Grande do Sul.

Entre as vantagens dessa disponibilidade de polinizadores e, a seguir, a dispersão de frutos e sementes (por animais, vento, água etc.) e, finalmente, temperatura, luminosidade e umidade adequadas para a germinação, crescimento e estabelecimento da nova planta. Sincronizando os ciclos vegetativo e reprodutivo entre indivíduos da mesma espécie, o controle sazonal da reprodução favorece fecundação cruzada e, portanto, a recombinação gênica, além de permitir que o desenvolvimento progênie (OTAROLA \& ROCCA 2014).

A frutificação não foi influenciada por nenhuma variável, permitindo hipotetizar que esta espécie está sujeita a variações bi-anuais (RUBIM et al. 2010). De qualquer forma, é possível inferir que a oferta de sementes maduras para coleta ocorre entre abril e final de maio (um mês após o pico de florescimento) para G. palustris na região da Serra Catarinense.

É importante destacar a colocação de ATHAYDE et al. (2009), que mencionam que a temperatura e incidência solar são importantes fatores na fenologia vegetativa e reprodutiva de espécies vegetais subtropicais, o que foi corroborado neste estudo, visto que folhas maduras, desfolhamento e floração correlacionaram-se significativamente com estes fatores abióticos. O fato do regime de chuvas não ter relação com as fenofases vai de encontro com o relatado por MARCHIORETTO et al. (2007), ATHAYDE et al. (2009) e FERRERA et al. (2017), devido a distribuição regular das precipitações anuais, não ocorre a restrição de água às plantas em regiões subtropicais.

Os órgãos vegetativos e reprodutivos de G. palustris mais utilizados na medicina popular são as flores, caules, folhas e raizes. Sendo assim, indica-se o melhor período para coleta de flores para consumo medicinal ao longo dos primeiros meses do ano. Já para ramos e folhas é desejável um crescimento satisfatório, o que acontece com intensidade durante a maior parte do ano, entretanto recomenda-se que as coletas não ocorram somente em um período para permitir a renovação dos órgãos vegetativos.

\section{CONCLUSÃO}

As fenofases senescência foliar, folhas maduras, e botões florais apresentaram correlação significativa 
com a temperatura e fotoperíodo, indicando que estas fenofases são influenciadas pelas variáveis meteorológicas. Galianthe palustris apresentou alta sincronia fenológica para brotação e baixa sincronia para as fenofases reprodutivas.

A floração de Galianthe palustris ocorre entre dezembro até junho enquanto a frutificação inicia em janeiro, com pico de frutos maduros em março. O brotamento é contínuo e o desfolhamento é gradual, com maior intensidade entre julho e agosto.

\section{AGRADECIMENTOS}

Os autores agradecem a Universidade do Estado de Santa Catarina (UDESC), pelo grau de Mestre concedido a primeira autora e ao Programa de Pós-graduação em Produção Vegetal, do Centro de Ciências Agroveterinárias (CAV), pelo ensino de excelência; a CAPES pela concessão da bolsa à primeira autora, para realização deste trabalho; a Klabin e a FAPESC (Fundação de Amparo à Pesquisa e Inovação do Estado de Santa Catarina), pelo apoio financeiro; a FIEPE (Fundação de Apoio ao Ensino, Pesquisa e Extensão) pelo apoio na gerência de recursos para esta pesquisa. Os agradecimentos são estendidos ao Engenheiro Florestal, Bruno Nascimento, pela elaboração do Abstract, às professoras Dra. Amanda Leite Bastos Pereira e Dra. Mari Lúcia Campos (UDESC/CAV), pelo apoio, discussões e leitura do manuscrito; aos proprietários das áreas onde o estudo foi realizado, senhores Irineu Wolff Furtado, Jodson Maia Furtado e Marcos Tigre de Oliveira, por concederem a permissão de acesso às áreas para o desenvolvimento desse estudo, e à especialista em Rubiaceae, Dra. Laila Mabel Miguel, professora de Botânica na Universidade Nacional do Nordeste e pesquisadora no Instituto de Botânica do Nordeste - IBONE, UNNE-CONICET, Corrientes, Argentina, pela confirmação da identidade da espécie Galianthe palustris (Cham. \& Schltdl.) Cabaña Fader \& E. L. Cabral, objeto deste estudo.

\section{REFERÊNCIAS}

ALMEIDA EM \& ALVES MAS. 2000. Fenologia de Psychotria nuda e P. brasiliensis (Rubiaceae) em uma área de Floresta Atlântica do sudeste do Brasil. Acta Botanica Brasilica 14: 335-346.

ALVARES et al. 2017. Modeling monthly meteorological and agronomic frost days, based on minimum air temperature, in Center-Southern Brazil. Theoretical and Applied Climatology 113: 177 - 191.

ATHAYDE EA et al. 2009. Fenologia de espécies arbóreas em uma floresta ribeirinha em Santa Maria, sul do Brasil. Revista Brasileira de Biociências 7.

BAWA KS \& BEACH JH. 1983. Self-incompatibility systems in the rubiaceae of a tropical lowland wet forest. American Journal of Botany 70: 1281-1288.

BENCKE CSC \& MORELLATO LPC. 2002. Comparação de dois métodos de avaliação da fenologia de plantas, sua interpretação e representação. Revista Brasileira de Botânica 25: 269-275.

BRASIL. 2006. Lei n ${ }^{\circ} 11.428$, de 22 de Dezembro de 2006. Diário Oficial [da] República Federativa do Brasil, Brasília, DF, 26 dez. 2006 - retificado em 9 jan. 2007. Disponível em: <http://www.planalto.gov.br/ccivil_03/_Ato20042006/2006/Lei/L11428.htm>. Acesso em: Abril de 2020.

CABRAL EL et al. 2011. Dos especies nuevas de Borreria (Rubiaceae), sinopsis y clave de las especies para Bahia, Brasil. Acta Botanica Brasilica 25: 255-276.

CARTAXO SL et al. 2010. Medicinal plants with bioprospecting potential used in semi-arid northeastern Brazil. Journal of Ethnopharmacology 131: 326-342.

CASTELLANI TT et al. 1999. Fenologia de uma comunidade de duna frontal no sul do Brasil. Acta Botanica Brasilica 13: 99-113.

COELHO CP \& BARBOSA. 2004. Biologia reprodutiva de Psychotria poeppigiana Mull. Arg. (Rubiaceae) em mata de galeria. Acta Botanica Brasilica 18: 481-489.

CONSERVA LM \& FERREIRA JC. 2012. Borreria and Spermacoce species (Rubiaceae): A review of their thnomedicinal properties, chemical constituents, and biological activities. Pharmacognosy Review 6 .

CORRÊA BJS et al. 2018.Fenologia e aspectos da biologia floral de Moquiniastrum polymorphum (Less.) G. Sancho Asteraceae) em plantio de restauração florestal. Acta Biologica Catarinense 5: 65-77.

DELPRETE PG \& JARDIM JG. 2012. Systematics, taxonomy and floristics of Brazilian Rubiaceae: an overview about the current status and challenges. Rodriguésia 63.

DENARDIN et al. 2018. Potencial alelopático de extratos de Borreria palustris. Anais do VI Congresso Latino-americano de Agroecologia 13.

DI STASI LC \& HIRUMA-LIMA CA. 2002. Plantas medicinais na Amazônia e na Mata Atlântica. São Paulo: Editora UNESP. ELIAS GA. et al. 2016. O Bioma Mata Atlântica. In: SANTOS R. et al. (Orgs.). Biodiversidade em Santa Catarina: Parque Estadual da Serra Furada. Criciúma: UNOESC.

FELIPPI M. et al. 2012. Fenologia, morfologia e análise de sementes de Cordia trichotoma (Vell.) Arráb. ex Steud. Ciência Florestal 3.

FERREIRA MC \& CONSOLARO HN. 2013. Fenologia e síndromes de polinização e dispersão de espécies de sub-bosque em um remanescente florestal urbano no Brasil central. Bioscience Journal 29. 
FERRERA TS et al. 2017. Fenologia de espécies nativas arbóreas na região central do estado do rio grande do sul. Ciência Florestal 27: 753-51.

FLORA DO BRASIL. 2020. Rubiaceae. In: Flora do Brasil 2020 em construção. Jardim Botânico do Rio de Janeiro, 2020. Disponível em: http://floradobrasil.jbrj.gov.br/reflora/floradobrasil/FB210. Acesso em: 06 de nov. 2020.

FOURNIER LA. 1974. Un método cuantitativo para la medición de características fenológicas en árboles. Turrialba 25.

GANEM RS. 2010. Conservação da biodiversidade: legislação e políticas públicas. Brasília: Câmara dos Deputados, Edições Câmara.

INOUYE DW. 2000. The ecological and evolutionary significance of frost in the context of climate change. Ecology Letters 3 (5): 457-463.

KERBAUY GB. 2008. Fisiologia vegetal. Rio de Janeiro: Guanabara Koogan.

Larcher, W. 2000. Ecofisiologia vegetal. São Carlos, SP Editora: Rima. 531p.

LOCATELLI E \& MACHADO IC. 2004. Fenologia das espécies arbóreas de uma Mata Serrana (Brejo de altitude) em Pernambuco, Nordeste do Brasil. In: PORTO KCL et al. (Org.). Brejos de altitude em Pernambuco e Paraíba: história natural, ecologia e conservação. Brasília: Ministério do Meio Ambiente.

MARCHIORETTO MS et al. 2007. Fenologia de espécies arbóreas zoocóricas em uma floresta psamófila no Sul do Brasil. Acta Botânica Brasilica 21.

MARTINI A et al. 2010. Fenologia de espécies nativas com potencial paisagístico. Semina: Ciências Agrárias 31.

MELO ASD \& BARBOSA MRV. 2007. O gênero Borreria G. Mey (Rubiaceae) na Mata do Buraquinho, João Pessoa, Paraíba. Revista Brasileira de Biociências 5: 627-629.

MING LC et al. 2012. Pesquisas agronômicas das plantas medicinais da Mata Atlântica regulamentadas pela ANVISA. Revista Brasileira de Plantas Medicinais 14: 131-137.

MMA. 2020. MINISTÉRIO DO MEIO AMBIENTE. Mata Atlântica. Disponível em: https://www.mma.gov.br/biomas/mataatl\%C3\%A2ntica_emdesenvolvimento. Acesso em: Abril de 2020.

MITTERMEIER R. A. et al. 2004. Hotspots revisited. Cidade do México: CEMEX.

MORELLATO LPC. et al. 1989. Estudo comparativo da fenologia de espécies arbóreas de floresta de altitude e floresta mesófila semi-decídua na Serra do Japí, Jundiaí, São Paulo. Revista Brasileira de Botânica 12.

MUNHOZ CBR \& FELFILI. 2005. Fenologia do estrato herbáceo-subarbustivo de uma comunidade de campo sujo na Fazenda Água Limpa no Distrito Federal, Brasil. Acta Botanica Brasilica 19: 979-988.

MYERS N. et al. 2000. Biodiversity hotspot for conservation priorities. Nature, v. 40.

NUNES YRF et al. 2005. Atividades fenológicas de Guazuma ulmifolia Lam.(Malvaceae) em uma floresta estacional decidual no norte de Minas Gerais. Lundiana 6: 99-105.

OKSANEN J. et al. 2010. Vegan: Community Ecology Package. R package version 1.17-0.

OLIVEIRA FC. et al. 2009. Avanços nas pesquisas etnobotânicas no Brasil. Acta Botânica Brasilica, 23: 590-605.

OTAROLA MF \& ROCCA MA. 2014. Flores no tempo: a floração como uma fase da fenologia reprodutiva. IN: RECH A R et al. (Org.). Biologia da polinização. Rio de Janeiro: Projeto Cultural.

RUBIM P et al. 2010. Variações interanuais na fenologia de uma comunidade arbórea de floresta semidecídua no sudeste do Brasil. Acta Botanica Brasilica 24: 756-764.

SILVEIRA et al. 2013. Fenologia e produtividade do amendoim em diferentes épocas de semeadura no Recôncavo Sul Baiano. Bioscience Journal 29.

SCHULZE et al. 2019. Plant Ecology. Berlin: Springer-Verlag.

SEMA. 2009. SECRETARIA DO MEIO AMBIENTE. Mata Atlântica Sul: Projeto de Conservação da Mata Atlântica no Rio Grande do Sul, PCMARS/ 2004-2009. Porto Alegre: SEMA.

SOUZA DNN et al. 2014. Estudo fenológico de espécies arbóreas nativas em uma unidade de conservação de caatinga no Estado do Rio Grande do Norte, Brasil. Biotemas 2.

TAIZ L \& ZEIGER E. 2013. Fisiologia Vegetal. Porto Alegre: Artmed.

TALORA DC \& MORELLATO LPC. 2000. Fenologia de espécies arbóreas em floresta de planície litorânea do sudeste do Brasil. Revista Brasileira de Botânica 23: 13-26.

VARJÃO RR et al. 2013. Rubiaceae Juss. de caatinga na APA Serra Branca/Raso da Catarina, Bahia, Brasil. Biota Neotropica 13: 105-123. 